\title{
Continuing medical education and burnout among Danish GPs
}

\author{
Anders Brøndt, Ineta Sokolowski, Frede Olesen and Peter Vedsted
}

\author{
ABSTRACT \\ Background \\ There has been minimal research into continuing \\ medical education (CME) and its association with \\ burnout among GPS. \\ Aim \\ The aim of this study was to investigate the \\ association between participating in CME and \\ experiencing burnout in a sample of Danish GPs.

\section{Design of study} \\ Cross-sectional questionnaire study.

\section{Setting} \\ All 458 active GPs in 2004, in the County of Aarhus, \\ Denmark were invited to participate.

\section{Method} \\ Data on CME activities were obtained for all GPs and \\ linked to burnout which was measured using the \\ Maslach Burnout Inventory - Human Services Survey. \\ The relationship between CME activity and burnout \\ was calculated as prevalence ratios $(P R)$ in a \\ generalised linear model.

\section{Results} \\ In total, 379 (83.5\%) GPs returned the questionnaire. \\ The prevalence of burnout was about $25 \%$, and almost \\ $3 \%$ suffered from 'high burnout'. A total of 344 (92.0\%) \\ GPs were members of a CME group or a supervision \\ group. Not being a member of either a CME group or \\ a supervision group was statistically significantly \\ associated with doubled likelihood of burnout (PR = 2.2). \\ Among GPs not making use of a practice facilitator, a \\ seven-fold higher likelihood of high burnout was found.

\section{Conclusion} \\ GPs who were not members of a CME group and did \\ not take part in outreach visits had a higher likelihood \\ of suffering from burnout and high burnout than those \\ who were members of a CME group or received \\ outreach visits. Therefore, not being a member of a \\ CME group could indicate that the GP is more likely to \\ suffer from burnout. Although the present study does \\ not unequivocally establish causality, it would be \\ interesting to see whether staying active in CME may \\ also prevent burnout among GPs.

\section{Keywords} \\ burnout; continuing medical education; general \\ practice; general practitioner
}

\section{INTRODUCTION}

Pressure on GPs has risen, patients have become more demanding, and governments want doctors to be more efficient and effective, and to provide better service. ${ }^{1,2}$ Many GPs experience more administrative work in their daily commitments and, as a consequence, may be more stressed, unsatisfied, and burnt-out., ${ }^{3,4}$ Burnout among GPs has been shown to be associated with suicide,,$^{1}$ impaired job performance, ${ }^{5}$ tendency toward substance abuse, ${ }^{6}$ less provision of preventive services, ${ }^{7}$ and negative effects on their mental health. ${ }^{8}$

Continuing medical education (CME) consists of educational activities to maintain, develop, or increase the knowledge, skills, and professional performance and relationships that a physician uses to provide services for patients, the public, or the profession. ${ }^{9}$ Studies have found that some CME activities give rise to better care processes and better patient outcomes than others. ${ }^{10}$ Maintaining high quality services in general practice therefore requires encouragement of $\mathrm{CME}$ activities.

It could be hypothesised that there is an association between GPs' experience of burnout and their participation in CME activities. Such an association would mean that a greater effort should be made to recruit those GPs who usually do not take part in CME. However, this remains a hypothesis as it has only been possible to identify a single study analysing the association between

A Brøndt, MD, researcher; I Sokolowski, MSc, statistician; F Olesen, MD, DMSc, professor, head of department; $P$ Vedsted, MD, PhD, senior researcher, Research Unit for General Practice, University of Aarhus, Aarhus, Denmark.

Address for correspondence

Anders Brøndt, Research Unit for General Practice, Institute of Public Health, University of Aarhus, Vennelyst Boulevard 6, DK-8000 Aarhus, Denmark.

E-mail: a.broendt@alm.au.dk

Submitted: 11 June 2007; Editor's response: 2 August 2007; final acceptance: 26 September 2007.

(c)British Journal of General Practice 2008; 58: 15-19.

DOI: 10.3399/bjgp08X263767 


\section{How this fits in}

Minimal research has been carried out into continuing medical education (CME) and its association with burnout among GPs. This study found that not being a member of a CME-group is associated with higher prevalence of burnout. Focus in the future should be on why GPs engage in CME, and if CME can prevent burnout among GPs. general practice CME and burnout. An Israeli study among family physicians and paediatricians found that doctors participating in CME activities were less likely to report burnout. ${ }^{11}$

The aim of the current study was to investigate the association between participating in CME and experiencing burnout using a sample of Danish GPs.

\section{METHOD}

In Denmark GPs are organisationally and financially encouraged to participate in postgraduate training, CME, and outreach visits. Each GP has a personal account that may pay for at least 3 full days of CME activities a year (including compensation for lost earnings and course fees). Furthermore, GPs have the opportunity to participate in locally financed CME groups, for which they are also paid a small fee.

All GPs in the County of Aarhus, Denmark have the opportunity to use, free of charge, the 'practice facilitator' - a model which advocates outreach visits which aim to facilitate desired changes in the GPs' clinical behaviour. In general, most GPs support this organisation of CME activities and most take part to some extent. ${ }^{12,13}$

\section{Study population}

In a cross-sectional questionnaire study, all 458 active GPs in May 2004 in the County of Aarhus were invited to participate. Four GPs were excluded: one was a member of the research group, and three were on leave.

\section{Questionnaire}

The 10-page self-administered questionnaire included scales on burnout and questions about CME activities and GP and practice characteristics. Burnout was measured by the Maslach Burnout Inventory - Human Services Survey (MBI-HSS), an international scale which is considered to be reliable and valid. ${ }^{14-16}$ This self-rating scale consists of 22 items forming three subscales. Each item is scored on a 7-point ordinal scale, where 'never' is scored 0 and 'every day' is scored 6 . The three subscales are: emotional exhaustion (9 items), which refers to reduced energy and decreased job enthusiasm; depersonalisation (5 items), which refers to cynicism and lack of empathy; and personal accomplishment (8 items), which refers to inefficacy.

Each dimension receives a score which, relative to normative population scores, is categorised as low or high. Burnout was defined by a high score on the emotional exhaustion subscale (>26) and/or on the depersonalisation subscale $(>9)$. High burnout was defined by a high score on the subscales for emotional exhaustion (>26) and depersonalisation $(>9)$, and a low score on the personal accomplishment subscale $(<34) .{ }^{14}$

CME was assessed by asking GPs if they were members of local CME groups or supervision groups (CME with a psychological approach as in the Balint groups), if they used the practice facilitator (outreach visits), and how many days during the past 2-year period they had spent on conferences, courses, and seminars relevant to general practice.

Non-responders were sent a reminder with a new questionnaire after 4 weeks. GPs were remunerated for responding.

\section{Analysis}

For each GP, scores were calculated on the three burnout subscales. Whether the scores reached burnout or high burnout was also recorded. Only GPs who had answered all items on a subscale were included in the analysis of subscale scores, and burnout and high burnout was only assessed for GPs who had answered all necessary items.

Days spent during a 2-year period on conferences, courses, and seminars relevant to practice were categorised into four groups: $0-5$, $6-9,10-17$, and more than 17 days. This classification was made because every GP in Denmark is entitled to at least 3 full days of course activity a year. GPs who were members of both a CME group and a supervision group were compared with GPs who were members of only one of the groups, and with GPs who were not members of either a CME group or a supervision group.

The association between feeling emotionally exhausted, depersonalised, having low personal accomplishment, suffering from burnout or high burnout, and CME activities was calculated. Associations were calculated as prevalence ratios (PRs) in a generalised linear model with log link for a binomial outcome.

Calculations were made of the crude PR and an adjusted PR including age, sex, practice organisation (solo practice, group practice, or partnership practice), number of enrolled patients per GP $(<1385$, 1385-1785, or $>1785$ patients), and weekly working hours (<36, 37-41, 42-46, 47-51, or $>51$ hours). 
Ninety-five per cent confidence intervals (Cl) were calculated for proportions and ratios with $P$ values of $5 \%$ or less considered statistically significant. Data were analysed using Stata 9.0.

\section{RESULTS}

In total, 379 (83.5\%) GPs returned the questionnaire. Characteristics of the study population are shown in Table 1. A total of 344 (92.0\%) GPs were members of a CME group or a supervision group. Nearly $75 \%$ of the doctors spent 10 or more days during a 2-year period on practicerelevant courses, conferences, and seminars.

It was found that $89 \mathrm{GPs}(24.1 \%, 95 \% \mathrm{Cl}=19.8$ to 28.8$)$ suffered from burnout and $10(2.8 \%, 95 \%$ $\mathrm{Cl}=1.3$ to 5.1 ) from high burnout. No statistically significant difference was observed between female and male GPs.

GPs who were members of neither a CME group nor a supervision group had a statistically significantly increased likelihood of suffering from burnout (Table 2). Among GPs who did not make use of the possibility of receiving outreach visits, a seven-fold higher likelihood of high burnout was seen. Regarding days spent on relevant courses, no significant association was found with burnout or scores on the subscales. However, spending more than 9 days on relevant activities over a 2year period, and especially more than 17 days, was associated with a tendency towards a decreased likelihood of burnout and high burnout.
Table 1. Demographic characteristics, practice organisation, and CME activity $(n=377)$.

\begin{tabular}{lcc} 
& $n$ & $\%$ \\
\hline Sex & 229 & 60.7 \\
Male & 148 & 39.3 \\
Female & \\
\hline Practice organisation & 24.4 \\
Single-handed practice & 92 & 8.5 \\
Group practice & 32 & 24.7 \\
Shared practice & 93 & 38.7 \\
Partnership practice & 146 & 3.7 \\
Not listed & 14 & \\
\hline CME & & 18.7 \\
Member of a CME group and a supervision group & 70 & 73.3 \\
Being a member of either a CME or supervision group & 274 & 8.0 \\
Neither a member of a CME nor of a supervision group & 30 & \\
Days spent in 2 years on GP-relevant activities & & 9.3 \\
0-5 & 34 & 16.4 \\
6-9 & 60 & 51.8 \\
10-17 & 190 & 22.6 \\
\hline 17 & 83 & $\mathrm{SD}$ \\
\hline & Mean \\
\hline Age, years & 51.8 & 6.7 \\
\hline Weekly hours of work & 44.2 & 8.8 \\
\hline Years in profession & 14.9 & 8.4 \\
\hline Age of planned retirement, years & 63.7 & 2.4 \\
\hline
\end{tabular}

CME = continuing medical education.

\section{DISCUSSION}

\section{Summary of main findings}

The study results show that GPs who were not

\section{Table 2. Association between burnout, high burnout, and participation in CME activities.}

\begin{tabular}{|c|c|c|c|c|c|c|c|c|c|}
\hline & \multirow[b]{2}{*}{$n$} & \multicolumn{4}{|c|}{$\begin{array}{c}\text { Burnout } \\
\text { (GPs with burnout, } n=89 \text { ) }\end{array}$} & \multicolumn{4}{|c|}{$\begin{array}{l}\text { High burnout } \\
\text { (GPs with high burnout, } n=10 \text { ) }\end{array}$} \\
\hline & & PR & $P R^{a}$ & $\mathrm{Cl}$ & $P$-value & PR & $P R^{a}$ & $\mathrm{Cl}$ & $P$-value \\
\hline $\begin{array}{l}\text { Making use of a } \\
\text { practice facilitator }\end{array}$ & 351 & 1 & 1 & - & - & 1 & 1 & - & - \\
\hline $\begin{array}{l}\text { Not making use of } \\
\text { a practice facilitator }\end{array}$ & 21 & 1.5 & 1.6 & 0.8 to 3.3 & 0.175 & 5.1 & 7.0 & 1.2 to 42.9 & 0.035 \\
\hline $\begin{array}{l}\text { Member of a CME group } \\
\text { or a supervision group }\end{array}$ & 274 & 1 & 1 & - & - & 1 & 1 & - & - \\
\hline $\begin{array}{l}\text { Member of a CME group } \\
\text { and a supervision group }\end{array}$ & 7.0 & 0.5 & 0.5 & 0.3 to 1.0 & 0.061 & 0.6 & 0.6 & 0.1 to 5.0 & 0.635 \\
\hline $\begin{array}{l}\text { Neither a member of a } \\
\text { CME group nor a member } \\
\text { of a supervision group }\end{array}$ & 30 & 1.6 & 2.2 & 1.2 to 3.0 & 0.010 & 1.3 & 1.3 & 0.1 to 12.1 & 0.806 \\
\hline \multicolumn{10}{|c|}{$\begin{array}{l}\text { Days spent on conferences, courses, } \\
\text { and seminars over } 2 \text { years }\end{array}$} \\
\hline $0-5$ & 34 & 1.0 & 0.9 & 0.4 to 1.8 & 0.679 & 1.0 & 1.5 & 0.1 to 18.2 & 0.759 \\
\hline 6-9 (reference) & 60 & 1 & 1 & - & - & 1 & 1 & - & - \\
\hline $10-17$ & 190 & 0.9 & 0.8 & 0.5 to 1.3 & 0.345 & 0.6 & 0.7 & 0.1 to 4.2 & 0.714 \\
\hline$>17$ & 83 & 0.6 & 0.5 & 0.3 to 1.1 & 0.081 & 0.8 & 0.8 & 0.1 to 6.0 & 0.824 \\
\hline
\end{tabular}

$P R=$ prevalence ratio. $P R^{\mathrm{a}}=$ adjusted prevalence ratio. $C M E=$ continuing medical education . 
members of a CME group or who did not take part in outreach visits were more likely to suffer from burnout and high burnout than GPs who were members of a CME group or took part in outreach visits. It was not possible to show an association between number of days spent on courses and burnout. The prevalence of burnout among Danish GPs was about $25 \%$, and almost $3 \%$ suffered from high burnout. One in three GPs were found to be lacking a sense of personal accomplishment, one in five suffered from depersonalisation, and one in 10 GPs was emotionally exhausted.

\section{Strengths and limitations of the study}

The strengths of this study were the use of an international validated scale for measuring burnout, a high response rate, and statistical precision. The high response rate indicates that the GPs found the questionnaire relevant. As the study was crosssectional, it is not possible to make any causal inference; for example, whether GPs would suffer from burnout less frequently if they participated in CME activities or, more reasonably, if the GPs who chose not to participate were those who suffered from burnout.

The validity of the burnout measure has been shown to be valid in cross-sectional studies. However, if the measure is unstable, for example if it depends too much on job stress on a particular day, the measure may be inaccurate. It has not been possible to find data on reproducibility of the MBIHSS. However, the MBI-HSS has been shown to be highly associated with mental health and job satisfaction, for example, ${ }^{17-19}$ which indicates that the measure is stable.

Although the study had a high response rate, a small group of physicians did not respond, which may provide a basis for possible selection bias. It is reasonable to assume that GPs experiencing burnout would have less energy and enthusiasm to complete the questionnaire. Given a higher prevalence of burnout among non-responders, the prevalence of burnout may therefore have been underestimated. The non-responding group would not have been expected to have participated in more CME activities, and a possible selection bias would not change the association found between CME and burnout.

CME activities were measured from GPs' selfreported use of outreach visits, membership of CME and supervision groups, and use of days on courses. The use of days on courses during a 2-year period may invite recall bias which may explain why no association was detected here.

\section{Comparison with existing literature}

The prevalence of burnout and high burnout among
GPs found in this study is supported by the findings of a Swiss study which showed that one-third of primary care physicians experienced burnout, and $2.8 \%$ experienced high burnout. ${ }^{18}$ Studies of UK and Italian GPs found higher levels of emotional exhaustion and depersonalisation, but lower values on personal accomplishment compared with the present findings. ${ }^{8,20}$

Only one study has been identified that examines burnout and CME among physicians. ${ }^{11}$ Kushnir et al found a negative association between CME activities and burnout among Israeli GPs. ${ }^{11}$ The authors suggested that $\mathrm{CME}$ and professional updating may reduce the level of burnout. The current study is not completely comparable to their study, however, as a different approach to measure CME and burnout was used.

\section{Implications for future research and clinical practice}

GPs who were not members of a CME group had a significant higher likelihood of suffering from burnout and high burnout than those who were members of a CME group. Therefore, not being a member of a group could indicate that these GPs may be more likely to suffer from burnout. Although the present study does not unequivocally establish causality, it seems reasonable to be aware of possible implications if a GP stops CME activities, or to encourage GPs to be a member of a CME group. However, it remains unanswered whether it is the group, the CME, or the combination of the two which is most important. Future research could also investigate whether CME groups may be more attractive to GPs with a similar suitable learning style and behaviour, which may indicate that the groups may not be inclusive enough.

\section{Funding body}

This study was funded by the Regional Committee on Quality Improvement in the County of Aarhus

\section{Ethics committee}

According to Danish law no ethical approval was necessary to conduct this study

\section{Competing interests}

The authors have stated that there are none

\section{Discuss this article}

Contribute and read comments about this article on the Discussion Forum: http://www.rcgp.org.uk/bjgp-discuss

\section{REFERENCES}

1. Gundersen L. Physician burnout. Ann Intern Med 2001; 135(2): 145-148.

2. Linzer M, Visser MR, Oort FJ, et al. Predicting and preventing physician burnout: results from the United States and the Netherlands. Am J Med 2001; 111(2): 170-175.

3. Murray A, Montgomery JE, Chang $\mathrm{H}$, et al. Doctor discontent A comparison of physician satisfaction in different delivery system settings, 1986 and 1997. J Gen Intern Med 2001; 16(7): 452-459.

4. Shanafelt T, Adjei A, Meyskens FL. When your favorite patient 
relapses: physician grief and well-being in the practice of oncology. J Clin Oncol 2003; 21(13): 2616-2619.

5. Parker PA, Kulik JA. Burnout, self- and supervisor-rated job performance, and absenteeism among nurses. J Behav Med 1995; 18(6): 581-599.

6. McCall SV. Chemically dependent health professionals. West J Med 2001; 174(1): 50-54

7. Mulligan K. Self care for general practitioners. Aust Fam Physician 1997; 26(7): 787-789.

8. Maslach C, Schaufeli WB, Leiter MP. Job burnout. Annu Rev Psychol 2001; 52: 397-422.

9. Accreditation Council for Continuing Medical Education. Glossary of terms and abbreviations. http://www.accme.org (accessed 5 October 2007).

10. Shanafelt TD, Bradley KA, Wipf JE, Back AL. Burnout and selfreported patient care in an internal medicine residency program. Ann Intern Med 2002; 136(5): 358-367.

11. Kushnir T, Cohen AH, Kitai E. Continuing medical education and primary physicians' job stress, burnout and dissatisfaction. Med Educ 2000; 34(6): 430-436.

12. Nielsen JM, Vedsted P, Olesen F. The postgraduate training of general practitioners in communication and counseling. A questionnaire survey in the County of Aarhus (In Danish). Ugeskr Laeger 2002; 164(7): 895-899.
13. Christensen KS, Rosendal M, Nielsen JM, et al. Educational outreach visits. Choice of strategy for interviewing general practitioners (In Danish). Ugeskr Laeger 2003; 165(14): 1456-1460.

14. Maslach C, Jackson SE, Leiter MP. Maslach Burnout Inventory. Palo Alto, California: Consulting Psychologists Press, 1996.

15. Kanste O, Miettunen J, Kyngas H. Factor structure of the Maslach Burnout Inventory among Finnish nursing staff. Nurs Health Sci 2006; 8(4): 201-207.

16. Rafferty JP, Lemkau JP, Purdy RR, Rudisill JR. Validity of the Maslach Burnout Inventory for family practice physicians. J Clin Psychol 1986; 42(3): 488-492.

17. Becker JL, Milad MP, Klock SC. Burnout, depression, and career satisfaction: cross-sectional study of obstetrics and gynaecology residents. Am J Obstet Gynecol 2006; 195(5): 1444-1449.

18. Goehring C, Bouvier GM, Kunzi B, Bovier P. Psychosocial and professional characteristics of burnout in Swiss primary care practitioners: a cross-sectional survey. Swiss Med Wkly 2005; 135(7-8): 101-108.

19. Grassi L, Magnani K. Psychiatric morbidity and burnout in the medical profession: an Italian study of general practitioners and hospital physicians. Psychother Psychosom 2000; 69(6): 329-334.

20. McManus IC, Winder BC, Gordon D. The causal links between stress and burnout in a longitudinal study of UK doctors. Lancet 2002; 359(9323): 2089-2090. 